'llu. Revista de Ciencias de las Religiones

ISSN: $1135-4712$

https://dx.doi.org/10.5209/ilur.75205

\title{
La intertextualidad entre Jc 5,12; Sal 68,19 (y sus versiones siríaca y aramea) y Ef 4,8. Una aproximación desde la estilística sociológica
}

\author{
Diego Pérez-Gondar ${ }^{1}$
}

Recibido: 3 de octubre de 2018 / Aceptado: 25 de febrero de 2019

Resumen. Algunas intuiciones de la Estilística Sociológica son eficaces para percibir mejor que la dependencia intertextual entre documentos es el reflejo de un dialogismo social concreto e histórico. Este enfoque ayuda a equilibrar la visión historicista y hace justicia a los textos. El trabajo analiza las dependencias entre Jc 5,12; Sal 68,19 y Ef 4,8, teniendo en cuenta sus diversas versiones y puntos de vista. Estos textos concretos muestran una dependencia intertextual donde la literalidad adquiere un valor secundario respecto de la novedad histórica que origina la nueva enunciación. Además, cada nuevo contexto rige el uso de la palabra anterior dotada de autoridad y lo hace para preservarla. El misterio pascual cristiano o la reconfiguración del judaísmo después de la destrucción del Templo (70 d.C.) condicionan el modo de actualizar un texto antiguo usándolo con fines nuevos.

Palabras clave: Intertextualidad; Estilística Sociológica; Bajtín; Jc 5,12; Sal 68,19; Ef 4,8.

\section{[en] The Intertextuality between Judg 5:12; Ps 68:19 (and its Syriac and Aramean Versions) and Eph 4:8. An approach from Sociological Stylistics}

\begin{abstract}
Some intuitions of Sociological Stylistics are effective to better perceive how the intertextual dependence among documents is the reflection of a concrete and historical social dialogism. This approach helps to balance the historicist vision and does justice to the texts. This work analyzes the dependencies between Judg 5:12; Ps 68:19 and Eph 4:8, taking into account their different versions and points of view. These concrete texts show an intertextual dependence in which literality takes a secondary value with respect to the historical novelty that originates the new enunciation. In addition, each new context governs the use of the previous word endowed with authority and does so in order to preserve it. The Christian paschal mystery or the reconfiguration of Judaism after the destruction of the Temple (70 AD) conditions the way of updating an ancient text using it with new purposes.
\end{abstract}

Keywords: Intertextuality; Sociological stylistics; Bakhtin; Judg 5:12; Ps 68:19; Eph 4:8.

Sumario. 1. Introducción. 2. Presentación metodológica. Dimensión dialógica de la comunicación. 2.1. El giro lingüístico y la intertextualidad. 2.2. Herramientas de análisis según la Estilística sociológica. 2.2.1. La estilización. 2.2.2. Uso paródico de la palabra ajena. 2.2.3. La polémica oculta. 3. Resultados obtenidos sobre las relaciones entre Jc 5,12, Sal 68,19 y Ef 4,8. 4. Discusión sobre la intertextualidad entre Jc 5,12, Sal 68,19 y Ef 4,8. 4.1. Relación entre Jc 5,12 (TM/LXX) y Sal 68,19 (TM/LXX). 4.2. Recepción de Sal 68,19 en sus versiones siríaca (Syr) y aramea (Tg Sal). 4.2.1. La versión siríaca. 4.2.2. La versión aramea. 4.3. Interpretación paulina de Sal 68,19 en Ef 4,8. 4.3.1. Opción a: Ef depende de Tg Sal/Syr. 4.3.2. Opción b: Tg Sal/Syr dependen de Ef. 4.3.3. Opción c: No hay dependencia entre Ef y Tg Sal/Syr. 5. Conclusiones. 6. Bibliografía

1 Universidad de Navarra

Correo electrónico: dpgondar@unav.es

ORCID iD: https://orcid.org/0000-0002-7761-1411 
Cómo citar: Pérez-Gondar, D. (2021), La intertextualidad entre Jc 5,12; Sal 68,19 (y sus versiones siríaca y aramea) y Ef 4,8. Una aproximación desde la estilística sociológica, en 'Ilu. Revista de Ciencias de las Religiones 24, 109-123.

\section{Introducción}

El uso particular de los textos del AT por parte de los autores del NT no es claro en la comunidad académica. Más allá de la genérica denominación de intertextualidad afirmativa de Kristeva - es decir, que el texto del NT le otorga autoridad al veterotestamentario-, el tratamiento de los textos venía clasificado según los términos de cita, mención o alusión. En el caso de las citas textuales, la concordancia o discordancia léxicas se estudiaban diacrónicamente, buscando la coherencia en la posible relación del texto del NT con los testigos hebreos y griegos del AT y las posibles acomodaciones por parte de los autores del NT. En este marco, que a veces ha desembocado en parallelomania ${ }^{2}$, uno de los extremos lo ocupa lo que se ha denominado «cita errónea». La relación entre Ef 4,8 y Sal 68,19 es un buen ejemplo.

Sal 68 es un salmo complejo. Desde el punto de vista sintáctico sigue siendo un verdadero reto. Algunos piensan que se trata de un texto muy antiguo, mientras que otros consideran que el autor lo arcaizó por motivos retóricos ${ }^{3}$. Además, es bien conocida la relación de algunas secciones de este salmo con el famoso Cántico de Débora en el contexto de la batalla contra Sísara (Jc 4-5). Por ese motivo, el recorrido que realizaremos en este estudio parte de Jc 5,12 (TM/LXX), pasa por Sal 68,19 (TM/LXX) y concluye con la interpretación judía de Sal 68,19, presente en su versión siríaca (Syr) y aramea (Tg Sal), así como la cristiana, cristalizada en Ef 4,8. Un dato significativo que conviene adelantar ya es que las versiones hebrea y griega de Jc 5,12 y Sal 68,19 no presentan diferencias significativas.

En una tesis que defendió en 2014, S. M. Ehorn estudiaba la cita de Sal 68,19 en Ef 4,8. Esta cita ha sido objeto de atención en múltiples ocasiones, pero sigue resultando un enigma ${ }^{4}$. Es indudable que el autor de Efesios cita el salmo. Lo que sorprende es que modifique el texto de Sal 68,19 en la línea de su propio discurso y cambie el verbo «recibir/tomar» por el verbo «dar» ${ }^{5}$. Ehorn apuntaba allí:

Esta misma etiqueta de «cita errónea» es a la vez esclarecedora y ofuscante cuando se usa en referencia a la cita de Sal 68,19 en Ef 4,8. En nuestra perspectiva moderna, el autor de Efesios se ha comportado en la redacción de su cita de una manera que, presumiblemente, tergiversa la fuente. La palabra citada no se conserva, sino que se interrumpe, se altera, se modifica. (...) Sin embargo, uno de los puntos clave (...) es que la alteración del texto de Sal 68,19 en Ef 4,8 no es un acto

\footnotetext{
Cfr. Sandmel 1962.

Cfr. Schökel 1992, I 867-893, Kraus 1995, II 73-92 y Zenger - Hossfeld 2005, 158-169.

Algunos de los principales estudios que han abordado la cuestión son: Rubinkiewicz 1975, Smith 1975, Lincoln 1982, Fitzmyer 1984, Harris 1988, Scholtus 2010, Ehorn 2012, Stafford 2013, y Ehorn 2014.

5 Adelantamos ahora los textos principales para facilitar la compresión. Sal 68,19 dice: «Subiste a las alturas, conduciendo los cautivos a la cautividad; tomaste a hombres como tributo, incluso rebeldes, para poner allí tu morada, ;oh Señor Dios!». Ef 4,7-8 dice: «A cada uno de nosotros fue dada la gracia conforme a la medida del don de Cristo. Por lo cual dice: "Subiendo a lo alto, llevó cautiva la cautividad, y dio dones a los hombres"». Los parecidos y las diferencias saltan a la vista y reclaman una explicación.
} 
indebido del autor. Más bien, representa los esfuerzos creativos del autor de Efesios, quien interpreta un texto profético a la luz de sus convicciones acerca de la resurrección-exaltación de Cristo. Alterando la forma del texto de «recibir» a «dar», el autor de Efesios es capaz de vincular su interpretación a una fuente autorizada y extraer precisamente el significado deseado. Desde una perspectiva moderna que mira hacia atrás, tal «salvajismo» en el manejo de una fuente puede parecer extraño. Sin embargo, en un contexto antiguo, tal alteración representa una forma importante en la que un autor puede mostrar el significado continuo de la palabra citada. De hecho, en ese contexto, uno podría incluso decir que ese «salvajismo» es la preservación de la palabra ${ }^{6}$.

Me propongo profundizar en esta afirmación de Ehorn para explicitar mejor los procesos implicados en esta crux interpretum concreta. La bibliografía especializada muestra que el debate versa sobre documentos y sus posibles dataciones y dependencias en una cierta locura denominada parallelomania. En este trabajo ensayo una metodología diversa que atiende al dialogismo presente en toda comunicación y me serviré de algunos instrumentos de análisis facilitados por la estilística sociológica de Bajtín. Dentro del planteamiento de Bajtín, que usa muchas veces expresiones metafóricas, se propone un sistema, como veremos. Un uso sistemático en los textos puede permitir un conocimiento más preciso y menos intuitivo del fenómeno de la intertextualidad.

\section{Presentación metodológica. Dimensión dialógica de la comunicación}

\subsection{El giro lingüístico y la intertextualidad}

Las ciencias sociales de la segunda mitad del siglo XX han estado regidas en gran parte por lo que se ha denominado linguistic turn, entendiendo por este giro lingüístico un estudio más profundo del lenguaje en su capacidad de ser portador de una tradición, de representar el mundo y de actuar en él.

Según O’Day, fue T. S. Elliot quien originó un cambio de perspectiva a través de su ensayo «Tradition and the Individual Talent» (1919). En este trabajo, Elliot abogó por la centralidad de la tradición literaria en la génesis de las nuevas creaciones artísticas, más allá del genio y originalidad de los autores ${ }^{7}$. Por lo tanto, si es común en la teoría literaria estudiar los contenidos de las obras mediante la tematización de las expresiones recibidas dentro de una determinada tradición, cuanto más dentro de los estudios bíblicos.

Teniendo esto en cuenta, considero que algunas intuiciones de Mijail Bajtín resultan muy iluminadoras y conectan con el planteamiento apuntado por Elliot. Prescindiendo de cuestiones formales de escuela me planteo acudir a unos textos concretos de Bajtín en los que se describen fenómenos dialógicos que explican de un modo más rico la intertextualidad. Después de una descripción genérica, estos fenómenos se aplicarán al estudio del objeto concreto de este trabajo.

Ehorn 2014, 384-385.

Cfr. O’Day 1999, 546. 


\subsection{Herramientas de análisis según la Estilística sociológica ${ }^{8}$}

Mijail Bajtín distinguía entre el uso objetual de una palabra ajena y el uso intencio$n a l^{9}$. En el primer caso se incluye todo fenómeno de mención -la cita, la alusión o eco- donde no comparece una imagen libre del lenguaje ajeno, es decir, donde el enunciador no es suplantado de ninguna manera por una voluntad estilizadora contemporánea, es decir, donde no se produce la hibridación de enunciados y lenguajes, donde sólo está presente una sola voz, una sola conciencia. Este modo objetual de componer obras usando textos anteriores no ofrece elementos para descubrir fenómenos de dialogismo social, no ofrece datos de cómo un intercambio dialógico de puntos de vista ha llegado a quedar cristalizados en los textos.

En los estudios bíblicos lo más frecuente es analizar los fenómenos de intertextualidad bajo esta perspectiva. Sin embargo, ese análisis arquitectónico que toma la palabra ajena anterior como un elemento pasivo e inerte no hace justicia a los elementos presentes en gran cantidad de textos donde se pueden descubrir fenómenos de hibridación. Es en esos casos de hibridación cuando se perciben intenciones anidadas en palabras ajenas.

Llamamos construcción híbrida al enunciado que, de acuerdo con sus características gramaticales (sintácticas) y compositivas, pertenece a un sólo hablante; pero en el cual, en realidad, se mezclan dos enunciados, dos maneras de hablar, dos estilos, dos «lenguas», dos perspectivas semánticas y axiológicas. Repetimos que, entre estos enunciados, estilos, «lenguas» y perspectivas, no existe ninguna frontera formal-compositiva ni sintáctica; la separación de voces y de lenguajes se desarrolla en el marco de un único todo sintáctico, frecuentemente en los límites de una proposición simple; incluso muchas veces, la misma palabra pertenece simultáneamente a dos lenguajes, tiene dos perspectivas que se cruzan en la construcción híbrida y tienen, por lo tanto, dos sentidos contradictorios, dos acentos ${ }^{10}$.

En muchos estudios bíblicos el énfasis en el análisis se centra en una vertiente objetual propia del método histórico. El objetivo del análisis se dirige a relacionar cronológicamente los documentos recuperados del pasado para establecer, mediante un análisis forense, qué testigos reconstruyen la verdad de los acontecimientos. La perspectiva de la que habla Bajtín desde su estilística sociológica es muy diversa. El pensador ruso pretende individuar el verdadero fenómeno dialógico social a través del estudio del uso de la palabra ajena presente en los textos. Lo interesante del análisis bajtiniano es el uso intencional y aquellas categorías que facilitan el análisis de la intertextualidad. El uso intencional implica una bivocidad o heteroglosia en la enunciación, pues la palabra ajena mencionada sufre una estilización consciente en la que se perciben dos voluntades representadas.

Este enfoque, poco presente todavía en el análisis de textos bíblicos, podría arrojar una luz más profunda que explicase las implicaciones intertextuales presentes en

\footnotetext{
Para una síntesis acerca de la primacía sociológica del lenguaje, $c f r$. Volóshinov 1973, 157s.

Para una introducción al mundo de la intertextualidad, cfr. Milán 2016, donde se recoge abundante bibliografía sobre el particular. De las obras de Bajtín, nos fijaremos en: Bajtín 1982, 1986 y 1989. Puede encontrarse una síntesis del pensamiento de Bajtín, Kristeva, Barthes, Genette y Riffaterre en Allen 2000. Un autor que ha dedicado muchos esfuerzos al estudio de la intertextualidad bíblica es Hays (cfr. Hays 1989, 2005, 2009 y 2016).

10 Bajtín 1989, 121s.
} 
el canon de Escrituras. Y esto es así porque nos ofrece ayudas para contrastar hipótesis de nivel sociológico-histórico y teológico con los propios textos tal como han sido recibidos en la comunidad ${ }^{11}$.

El propio Bajtín afirmaba que el dialogismo presente en los textos -incluso en aquellos monológicos- es apenas una tempestad dentro de un vaso de agua respecto de los grandes debates que se han dado entre los diversos puntos de vista presentes en la confrontación social ${ }^{12}$.

Se puede decir que el objeto principal de nuestro examen, su protagonista, será la palabra bivocal que se origina ineludiblemente en las condiciones de la comunicación dialógica, es decir, en las condiciones de la vida auténtica de la palabra ${ }^{13}$.

De los fenómenos artísticos descritos por Bajtín, aquí nos interesan especialmente tres: la estilización, la polémica oculta y la parodia. Las posibilidades reales de anidamiento de perspectivas en el uso de la palabra ajena son más numerosas, pero serán suficientes aquí estas tres posibilidades. Bajtín decía que:

Todos estos fenómenos, a pesar de sus diferencias importantes, se caracterizan por un rasgo común: la palabra en ellos posee una doble orientación; como palabra normal, hacia el objeto del discurso; como otra palabra, hacia el discurso ajeno. Si no conocemos este segundo contexto y percibimos la estilización o la parodia tal como se percibe el discurso habitual, dirigido tan sólo a su objeto, no comprenderemos la esencia de estos fenómenos, la estilización se percibirá por nosotros como estilo, la parodia solamente como una mala obra ${ }^{14}$.

\subsubsection{La estilización}

De los tres tipos de fenómenos, el primero que debemos describir es la estilización. Esta operación dialógica está muy cerca de la imitación, es decir, de un mero uso objetual de la palabra ajena. En la imitación se produce una fusión tal de voces que no se puede hablar de bivocidad. En la estilización el productor de la imagen libre de la palabra ajena presupone un estilo y usa un discurso orientado al objeto, pero

aprovecha la palabra ajena precisamente como tal y con ello confiere un ligero matiz de objetivación, pero en realidad esta palabra no llega a ser objeto, lo que al estilizador le importa es el conjunto de procedimientos del discurso ajeno, precisamente en tanto que expresión de un peculiar punto de vista. Por eso una cierta sombra de objetivación cae sobre éste, a consecuencia de lo cual se vuelve con-

11 Esos fenómenos de estilización son especialmente significativos porque no sólo atestiguan un dialogismo temático entre dos voces o conciencias (bivocidad) a través de sus enunciados, sino que se puede ver más allá un diálogo entre lenguajes, es decir, entre distintos puntos de vista. Para un ejemplo de estudio de esos fenómenos de dialogismo a nivel no tanto de los enunciados concretos, sino a través de los lenguajes usados puede verse Mandolfo 2007. En este estudio, el autor describe el efecto dinámico de modificación de los estilos de los salmos de lamentación al cambiar las circunstancias históricas. De ese modo se presenta una corrección ciertamente pertinaz a la orientación de H. Gunkel respecto a los géneros literarios y su relación con el Sitz im Leben propio.

12 Cfr. Bajtín 1989, 142.

13 Bajtín 1986, 269.

14 Ibid., 270. 
vencional. El discurso objetual de un personaje nunca es convencional, éste siempre habla seriamente. La actitud del autor no penetra en el interior de un discurso, el autor lo observa desde el exterior.

La palabra convencional siempre es bivocal. Sólo aquello que alguna vez no fue convencional puede llegar a serlo. Este significado inicial, directo y no convencional, ahora sirve a otros propósitos que se posesionan de la palabra y la hacen convencional ${ }^{15}$.

La estilización implica un desarrollo de sentido en una determinada dirección. El autor usa la palabra ajena para su propio fin, pero no puede existir su enunciación si su referencia es demasiado diversa a la del enunciador en la palabra ajena. En cierto modo se puede hablar de una refracción de sentido. En la estilización se produce una nueva orientación en la intención comunicativa. Es cierto que sigue existiendo una cierta continuidad entre la palabra antigua y la nueva enunciación. Existe una conexión porque se hace presente un convencionalismo que reclama un ambiente equiparable. Se hace necesario que el setting o cronotopo nuevo -la ambientación-conecte con el anterior, aunque ahora los fines comunicativos sean algo diversos.

A modo de resumen se puede decir que la estilización consiste en la reproducción de una expresión anterior conocida, que ese uso se caracteriza por su convencionalismo, es decir, se deja notar en esa mención un respeto a un tema que se considera en cierto modo canonizado y estandarizado, aunque el autor desarrolla su propia enunciación hacia una nueva orientación de sentido.

\subsubsection{Uso paródico de la palabra ajena}

En la parodia ${ }^{16}$, sin embargo, la brecha entre las dos conciencias en diálogo es radical.

Al igual que en la estilización, el autor habla mediante la palabra ajena, pero, a diferencia de la estilización, introduce en tal palabra una orientación ajena. La segunda voz, al anidar en la palabra ajena, entra en hostilidades con su dueño primitivo y lo obliga a servir a propósitos totalmente opuestos. La palabra llega a ser arena de lucha entre dos voces (...); en la parodia, las voces no sólo aparecen aisladas, divididas por la distancia, sino que también se contraponen con hostilidad. Por eso la palpabilidad deliberada de la palabra ajena en la parodia debe ser sobre todo ostensible y marcada. Los propósitos del autor, por su parte, deben ser más individualizados y $\operatorname{completos}^{17}$.

El uso paródico de la palabra ajena, por tanto, es un modo de oponer ideas mediante una reflexión del lenguaje. En este caso se utiliza la palabra ajena, pero el texto posee los elementos suficientes, con sus marcadores específicos, para hacer entender al lector el nuevo sentido. La nueva orientación paródica se opone al senti-

$15 \quad$ Ibid., 276.

16 Puede resultar extraño usar el término parodia. De modo habitual esta palabra designa a una imitación burlesca. Sin embargo, pienso que merece la pena mantener la expresión, aunque no para denotar burla o ironía, sino para expresar un punto de vista opuesto de una determinada realidad.

17 Bajtín 1986, 282. 
do anterior del texto $-\mathrm{o}$ al menos lo modifica sustancialmente-, aun usando las mismas expresiones del enunciador primero.

\subsubsection{La polémica oculta}

El tercer fenómeno que resulta útil para el análisis es la polémica oculta. En múltiples ocasiones el autor no usa explícitamente la palabra ajena, sino que ésta está presente de un modo implícito y es a través del enunciado del autor donde se crea una imagen del discurso ajeno a través de su propia enunciación, pues responde con su punto de vista al punto de vista del enunciador primero, ahora silenciado. Esto es muy típico en los diálogos ocultos donde un personaje habla y va respondiendo al interlocutor que sólo se le percibe por lo implícito de la respuesta que va dando quien habla.

Tanto en la estilización como en la parodia (...) el autor utiliza las palabras ajenas para expresar sus concepciones propias. En la tercera variante [la polémica oculta] la palabra ajena queda fuera del discurso del autor, pero éste la toma en cuenta y se refiere a ella. Aquí la palabra ajena no se reproduce con una interpretación nueva, sino que actúa, influye o de alguna manera determina la palabra del autor permaneciendo fuera de ella. (...) En la polémica oculta la palabra del autor está orientada hacia su objeto como cualquier otra palabra, pero cada aserción acerca de su objeto se estructura de tal manera que permite, aparte de su significado temático, acometer polémicamente en contra de la palabra ajena con un mismo tema, en contra de una aserción ajena de un mismo objeto. La palabra orientada hacia su objeto choca en el mismo objeto con la palabra ajena, ésta no se reproduce, sino que apenas se sobreentiende; si no hubiese existido esta reacción a la palabra ajena sobreentendida, toda la estructura del discurso habría sido diferente. (...) En la polémica oculta la palabra ajena es rechazada y este rechazo determina la palabra del autor en la misma medida en que lo hace el mismo tema, lo cual cambia radicalmente la semántica de la palabra: junto con el significado objetual aparece otro significado orientado hacia la palabra ajena. No se puede comprender plena y sustancialmente un discurso semejante si se toma en cuenta únicamente su significado objetual directo. La matización polémica del discurso aparece en otros indicios puramente lingüísticos, en la entonación y en la construcción sintáctica, etc. ${ }^{18}$.

La polémica oculta implica un debate entre puntos de vista opuestos. Sin hacer referencia de un modo explícito a la palabra ajena, aunque refiriéndose a ella de modo implícito en el nuevo enunciado, el autor refleja una opinión diversa que sólo se puede construir en polémica con el enunciado ajeno. En este fenómeno se pueden producir diversas orientaciones, en la estilización sólo se puede desarrollar la orientación que está presente en el enunciado original. Por otra parte, no debemos olvidar que estas posibilidades de la creación lingüística suelen darse cuando existe un diálogo temático que implica un ambiente social concreto en evolución en el interior de una memoria comunicativa viva. Cada nueva etapa en ese proceso genera nuevos cronotopos condensados en los textos. 


\section{Resultados obtenidos sobre las relaciones entre Jc 5,12, Sal 68,19 y Ef 4,8}

Los textos concretos objeto de estudio aumentan debido a las versiones siríaca y aramea de Sal 68. La metodología empleada no ofrece elementos para dirimir las cuestiones cronológicas por lo que vamos a considerar todas las posibilidades de dependencia textual. Es claro que el objetivo es conocer mejor los procesos dialógicos y la enunciación de diversos puntos de vista en un entorno que usa palabras percibidas con autoridad en un mundo en el que toda novedad histórica plantea un reto a la tradición.

Respecto a los textos que nos ocupan, si aplicamos los conceptos descritos más arriba -estilización, polémica oculta y uso paródico-, podemos afirmar lo siguiente:

- Sal 68,19 (TM/LXX) es una estilización del texto de Jc 5,12 (TM/LXX).

- Si admitimos que Sal 68,19 (Syr/Tg) y Ef 4,8 no son dependientes uno del otro:

- Sal 68,19 (Syr/Tg) es una polémica oculta de Sal 68,19 (TM/LXX).

- Ef 4,8 es una polémica oculta de Sal 68,19 (TM/LXX) en una línea diferente del punto anterior.

- Si admitimos que Sal 68,19 (Syr/Tg) y Ef 4,8 dependen uno del otro, el documento posterior ofrecería una versión paródica del documento anterior.

\section{Discusión sobre la intertextualidad entre Jc 5,12, Sal 68,19 y Ef 4,8}

\subsection{Relación entre Jc 5,12 (TM/LXX) y Sal 68,19 (TM/LXX)}

En los capítulos 4 y 5 del libro de los Jueces primero se recoge la narración de los hechos de la batalla en el valle de Yizreel y luego se incluye el poema o cántico de Débora y Barak. En el canto del capítulo 5, como los acontecimientos ya se conocen, el canto es fácil de seguir porque reproduce la trama anterior. Sin embargo, a la hora de expresar la exaltación de los acontecimientos, el poema muestra la frescura de lo inmediato y el narrador se hace contemporáneo a los acontecimientos de tal manera que, cuando invita a Débora y a Barak a actuar, lo hace con imperativos que hacen referencia a un acontecimiento todavía no verificado, pero que el lector conoce como ya acontecido.

En esta primera fase del recorrido intertextual encontramos un monte, alguien que asciende a él, un contexto de lucha en el que se produce una victoria asombrosa y un botín. Al mismo tiempo hay un personaje poderoso que ha sido derrotado y un colectivo que se ve beneficiado y fortalecido como consecuencia del curso de los acontecimientos.

El texto base hebreo dice ${ }^{19}$ :

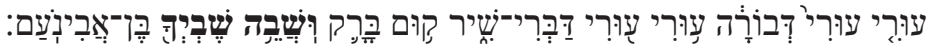

El narrador anima a los protagonistas de la gesta con una bella aliteración: «iArriba, arriba, Débora! ¡arriba, arriba, canta tu canción! ¡Levántate, Barak, apresa a tus

19 Ellinger-Rudolph 1977, 407. 
cautivos, hijo de Abinoam!». Este setting temático se conservará, aunque modificado en parte, en cada etapa del recorrido de la expresión שבה + שבי apreciar, se trata de una forma redundante del verbo שבה. En efecto, su objeto directo שבי proviene de la misma raíz. Esto constituye un ejemplo de una expresión de verbo más acusativo interno ${ }^{20}$.

Debido a las conexiones intertextuales posteriores, conviene detenerse en la versión griega del texto. Los LXX traducen el texto de Jc 5,12 según la recensión B del

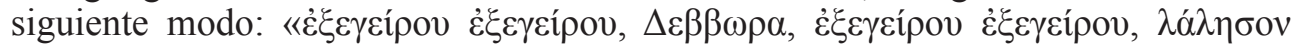

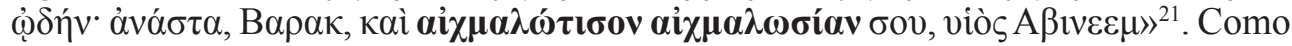
puede comprobarse, la versión griega B sigue a la hebrea con fidelidad. Quizás lo único reseñable de esta versión es que mantenga en singular el término ai $\chi \mu \alpha \lambda \omega \sigma i ́ \alpha$. En las versiones modernas, siguiendo a la Vulgata, este término abstracto singular (cautividad) es vertido en un concreto plural (captivos/cautivos).

Cuando este hito de la historia sagrada (Jc 4-5) se incluye en la gran epopeya de Sal 68, el término resaltado arriba pasa del imperativo qal a un perfecto qal. Esto es así porque en el salmo, la expresión se refiere a un pasado común. La frase hebrea de Sal 68,19 dice ${ }^{22}$ :

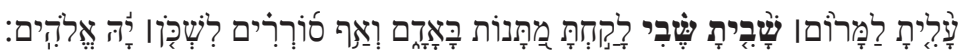

Asistimos ahora a un uso de palabra ajena. El salmista recoge la expresión antigua de Jc 5,12. Aquella expresión recibe un uso en el que el lenguaje del primer enunciador (el lenguaje representado) es situado en una nueva perspectiva temática e ideológica a través de una imagen que muestra un estilo nuevo y una relación dialógica en cuanto a la temática. El salmo habla del pasado celebrado en un nuevo presente. Por ese motivo la expresión representada comparece ahora en pasado. Además, fruto del lenguaje poético hebreo, necesita de una expresión complementaria. En efecto, se añade una sentencia para formar el paralelismo, que en este caso es sintético o progresivo. El versículo se puede traducir como: «Subiste a las alturas, has cautivado "la cautividad/cautivos" "); has tomado a hombres como tributo, incluso rebeldes, para poner allí tu morada, joh Señor Dios!». Hemos pasado de un lenguaje poético-épico vivo a uno de tipo poético-cultual solemne. Además, la expresión «has cautivado "la cautividad/cautivos"», un tanto enigmática, ahora se hace más precisa al añadir «has tomado tributo de [entre] los hombres». Los términos aluden al botín tomado de los despojos de la batalla en la que Sísara es vencido.

20 Esta peculiar construcción recurrente hebrea se encuentra en Nm 21,1; Dt 21,10; Jc 5,12; 1 R 8,46; 2 Cro 6,3638; 28,5.17 y Sal 68,19. Cfr. también Is 14,2.

21 Rahlfs 1979, 424. «Despierta, despierta, Débora, despierta, despierta, entona un canto; levántate, Barak, y esclaviza a tu esclavitud, hijo de Abinéem» (Fernández Marcos-Spottorno Díaz-Caro 2011, 103). La tradición textual del griego de Jc es doble. Un texto más extenso aparece en la recensión A donde la expresión objeto de

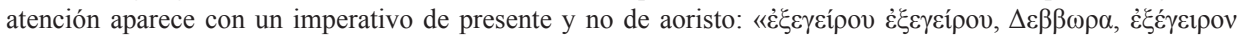

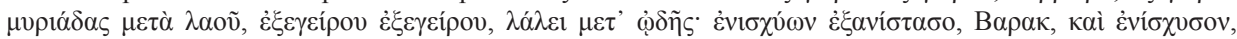

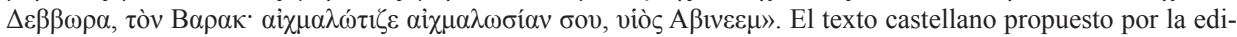
ción de Fernández Marcos dice: «Despierta, despierta, Débora, despierta a miles con el pueblo, despierta, despierta, habla con un canto; levántate con fuerza, Barak. Débora, fortalece a Barak; esclaviza a tu esclavitud, hijo de Abinéem (Ibid.).

22 Ellinger-Rudolph 1977, 1147s. 
La versión de los LXX (Sal 67,19) ${ }^{23}$ del texto no difiere mucho del TM: «ảvé $\beta \eta \varsigma$

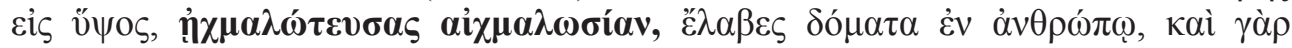

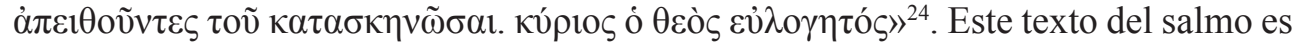
el que va a estar directamente relacionado con Ef 4,8 como veremos más adelante.

Lo más llamativo de Sal 68,19 es, quizás, el cambio de sujeto al que se dirige el salmista. En Jc 5,12 el poeta dirige los deícticos a Débora y a Barak. En Sal 68,19, el salmista está describiendo el pasado hablando en segunda persona del singular referido a Dios. El salmista se dirige al Señor recordando que fue Él quien ascendió al monte llevando cautivos consigo. En el conjunto del salmo se ha producido una trasposición del setting temático. El héroe victorioso es Dios y el contexto es el Éxodo, la victoria es sobre el faraón y las demás naciones que se oponían al Pueblo en la travesía por el desierto, y los cautivos en realidad son liberados. Todo hace pensar en el uso de un lenguaje propio del poeta que compuso el Canto de Débora. Ese canto de tipo épico-epicínico es usado ahora de manera dialógica en un nuevo contexto. Dios aparece como un héroe que salva a su pueblo. El resultado es habitar en el lugar señalado, incluso a pesar de las rebeldías. En el fondo se percibe una cierta oposición en los términos porque los cautivos que son tomados en el fondo son los que se benefician del nuevo don: la liberación del enemigo (Faraón) y la posesión de la Tierra. El uso de la palabra ajena aquí está cargado de una cierta oposición: los actantes se mantienen en un nivel teórico, aunque varían en la implementación concreta: Dios ocupa el lugar de Débora y Barak; el Faraón sustituye a Sísara (y Yabín); el Horeb o Sinaí es el nuevo Tabor; los restos del ejercito cananeo son sustituidos por los hebreos que salen de Egipto y las riquezas obtenidas, ahora se concretan en la tierra prometida. Por otra parte, en la versión griega, aun siguiendo con fidelidad al hebreo, se refuerza la expresión desde el punto de vista fonético (ท̣ $\chi \mu \alpha \lambda \omega ́ \tau \varepsilon v \sigma \alpha \varsigma$ $\left.\alpha^{i} \chi \mu \alpha \lambda \omega \sigma i \alpha v\right)$ debido a que la cadena que se repite ocupa cinco sílabas en vez de las dos de la versión hebrea.

Desde un punto de vista dialógico, los elementos destacados hasta ahora hacen pensar que el fenómeno intertextual presente aquí es el de la estilización. En líneas generales las dos conciencias presentes están de acuerdo, aunque la contemporánea desarrolla el sentido del texto anterior en la medida de sus intereses: en este caso el desarrollo es de tipo histórico-celebrativo. Además, se percibe un tono lleno de convencionalismo.

\subsection{Recepción de Sal 68,19 en sus versiones Siríaca (Syr) y Aramea (Tg Sal)}

\subsubsection{La versión siríaca}

La traducción siríaca de Sal 68,19 es un ejemplo claro de las interpretaciones realizadas del texto ${ }^{25}$. Aunque la tradición manuscrita es doble, ésta arroja una luz interesante sobre la ambigüedad presente en el TM y los LXX. En esta versión judía del s. I o II d.C. el traductor escribe: «Tú has ascendido a lo alto y has tomado cautiva la cautividad y has dado dones a los hijos de los hombres». Otra versión dice: «y has

23 Rahlfs 1967, 190.

24 La traducción que ofrece la edición de Fernández Marcos dice: «Has subido a lo alto, has hecho cautiva la cautividad, has recibido dones de hombre, también cuando desobedecían para acampar. El Señor Dios sea bendito» (Fernández Marcos-Spottorno Díaz-Caro 2013, 100).

25 Cfr. Walter 1980, 74. 
tomado dones para los hijos de los hombres». El nuevo enunciador se refiere a los hebreos como aquellos a los que Dios llena de dones. La traducción dice ahora lo contrario en la parte final de la frase. Es Dios quien da dones a los hombres. No es Dios el receptor de los hombres como dones.

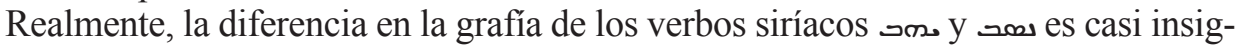
nificante. Las dos expresiones siríacas en el fondo dicen lo mismo y cambian la expresión original que resulta extraña. Ahora, en Syr, Dios es concebido como el dador de dones a su pueblo. Ahora bien, este uso implica un añadido de material realizado por el estilizador. Realmente el texto no contiene explícitamente la palabra ajena a la que sin duda alude. El nuevo enunciador está realizando una oposición: el texto es testigo de una hostilidad encubierta. Este modo de entender el texto resulta un tanto enigmático. Sin embargo, al situarlo en el contexto judío y en el conjunto de su literatura religiosa, no es tan extraño ${ }^{26}$. Quedará claro enseguida con la traducción aramea.

\subsubsection{La versión aramea}

En el ámbito rabínico Tg Sal 68,19 ofrece otro ejemplo de uso de una palabra ajena. El texto del salmo ahora posee unos añadidos que sitúan el contexto de un modo diferente. El setting temático ha cambiado, aunque el sistema actancial se mantiene. En este nuevo entorno rabínico es conocida la centralidad de Moisés. Realmente el testigo que analizamos ahora es tardío (s. V. d.C. quizás), pero podemos suponer que recoge material interpretativo antiguo. El texto dice: «Subiste al firmamento, oh profeta Moisés; capturaste cautivos, has enseñado las palabras de la Torá, has dado regalos a los hijos de los hombres, hasta al obstinado que se convirtió arrepentido, y la gloriosa presencia del Señor Dios permanece sobre ellos $\rangle^{27}$.

En el nuevo entorno ideológico, al traducir Sal 68 al arameo, se produce una nueva formulación de la enunciación anterior. Ahora Moisés se sitúa en el papel central, ocupado por Dios en el paso anterior. Además, la expresión general de los dones tomados de los hombres (TM/LXX) o dados a los hombres (Syr/Tg) se concreta en el don de la enseñanza de las palabras de la Torah, que hacen presente la gloria del Señor. ¿Qué acontecimiento podría explicar este cambio de punto de vista? Sin duda, una hipótesis más que razonable sería la destrucción del templo de Jerusalén en el 70 d. C. En efecto, si pensamos en el judaísmo del s. II d.C., centrado ya de modo radical en torno a la Torah y a la figura de Moisés, cuando el templo ya no existe y no hay esperanza de una inmediata restauración, es perfectamente posible comprender un cambio de ambiente que explique un uso polémico del texto antiguo. Se ha producido una discontinuidad en la memoria colectiva, un desastre que ha de ser asimilado en una nueva síntesis que haga avanzar al pueblo ${ }^{28}$. Es fácil percibir un debate entre una visión anterior nostálgica cargada de convencionalismo y una apertura en continuidad. El fenómeno previsible aquí es la polémica oculta. El texto de Syr y, especialmente el de Tg Sal, parecen manifestar este tipo de dialogismo.

26 Es común en las fuentes rabínicas interpretar Sal 68,19 referido a Moisés. En esos textos se muestra a Moisés subiendo a lo alto para entregar la Ley a los hombres. En las representaciones recogidas en estas obras, los antagonistas de Moisés son los ángeles. Cfr. ARN A 2,7; ExR 28,1; 33,3; RuthR 2,3 y PRE 46,3. Por motivos de extensión no es posible analizar ahora de estos textos.

$27 \quad$ Stec 2004, 131.

28 El cambio de orientación también se debe a que, contrariamente a la visión anterior donde el Faraón había sido derrotado, ahora quienes han sido derrotados son los judíos por parte de los romanos. 


\subsection{Interpretación paulina de Sal 68,19 en Ef 4,8}

La tradición paulina usa también la palabra ajena de Sal $68,19^{29}$. Y lo hace en su reflexión sobre la obra de Jesucristo. En el v. 7 dice: «A cada uno de nosotros fue dada la gracia conforme a la medida del don de Cristo». En el debate sobre Cristo como el nuevo Moisés, no extraña que cuando Ef 4,8 alude a Sal 68,19 diga: « $\delta$ tò

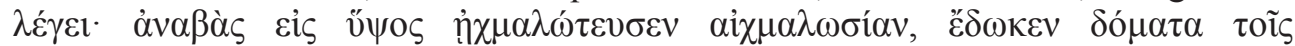
$\dot{\alpha} v \theta \rho \omega ́ \pi 01 c)^{30}$. Después de una fórmula estándar de citación - «por lo tanto [la Escritura] dice:...»-, aparece la nueva enunciación del texto antiguo: «Subiendo a lo alto, llevó cautiva la cautividad, y dio dones a los hombres». Ahora, lo alto, hace referencia a la muerte y resurrección de Jesús y los dones son la gracia derramada sobre los hombres, en especial los carismas necesarios para la edificación del reino instaurado en Cristo $^{31}$.

Es claro que el autor de Efesios usa los LXX, que a su vez reproduce el TM. Lo que no podemos determinar es si lo hace directamente o a través de la interpretación judía contemporánea. Ahora bien, lo que sí parece seguro es que produce una imagen relevante del texto del salmo para sus lectores. No se trata de una mera mención, sino un uso intencional en un nuevo contexto ideológico. En este caso o estaríamos ante una polémica oculta (desde Sal 68,19 [TM/LXX]) en la que Jesús ocupa el lugar de Dios o en un uso paródico (desde Tg Sal/Syr) si pensamos en el lugar de Moisés en la comprensión rabínica.

La metodología aplicada no puede resolver las cuestiones cronológicas por lo que contemplaremos todas las opciones posibles: a) El punto de vista de Efesios depende del manifestado en el Tg Sal y Syr, b) El punto de vista condensado en el Tg y Syr depende de la interpretación cristiana expresada en Ef; y c) Ambas líneas interpretativas se producen de modo independiente desde el texto hebreo y griego del salmo. De las tres opciones, b) parece muy difícil, a) es posible y c) es la más factible.

\subsubsection{Opción a: Ef depende de Tg Sal/Syr}

Una observación morfosintáctica de Ef 4,8 percibe las modificaciones claras que ha sufrido el texto. En efecto, aunque sigue en pasado, la construcción de participio de aoristo más aoristo en tercera persona habla de una concatenación: fruto de aquel ascenso a lo alto, Jesús tomó posesión de los cautivos y dio dones a los hombres. El uso paulino es idéntico al rabínico, pero en vez de Moisés y la Torah, en el nuevo setting temático, el dador es Jesucristo y el don es la gracia comunicada a los fieles, que surge del triunfo pascual.

Podemos pensar en el ambiente social en el que se produce el debate entre judeocristianos y judíos. Éstos últimos no aceptan a Jesús como el Mesías esperado. Todo indica, por tanto, una polémica a través de un uso paródico del texto anterior. La imagen creada de la palabra ajena es aquí una confrontación inserida según el patrón de este fenómeno dialógico. El texto reproduce la palabra ajena, aunque sustituye los deícticos anteriores por elementos referidos a Cristo: usa para su fin propio una palabra ajena anterior manifestando una oposición clara a esa interpretación. De ese

\footnotetext{
Para un status quaestionis acerca de la interpretación paulina del AT, cfr. González 2016.

Nestle-Aland 2012, 596.

Para profundizar en la función mediadora de Cristo en el NT, $c f r$. González 2017.
} 
modo, el fenómeno intertextual manifiesta un debate de ideas y de puntos de vista que conocemos presente en otros textos del NT.

De todos modos, sería un error entender el proceso descrito como si cada eslabón poseyese una dinámica atomizada y aislada. Es claro que el uso paródico de Ef 4,8 respecto de Syr/Tg Sal 68,19 no se entiende sin ser respuesta al uso mediante la polémica oculta que el judaísmo rabínico habría realizado respecto a su visión tradicional. Recordemos que esa visión, anterior al 70 d.C., estaba expresada en Sal 68,19 según el TM y los LXX.

Desde el punto de vista de la bivocidad o heteroglosia, si aceptamos esta opción, el debate presente en Ef 4,8 es muy rico. El punto de vista cristiano de Ef 4,8 se expresaría mediante una reflexión paródica: usaría un punto de vista judío al que se opone, usando la misma palabra, pero realizando un cambio de cronotopo y de deícticos.

\subsubsection{Opción b: Tg Sal/Syr dependen de Ef}

Aunque históricamente parece muy improbable, se podría proponer otra hipótesis. El autor de Efesios -incluso antes del 70 d.C.- podría haber realizado un uso en polémica oculta respecto al TM y a los LXX. Si consideramos Efesios como una epístola auténtica, cabría esta posibilidad: concebir una oposición al templo, una institución innecesaria ya en la nueva economía cristiana. Además, desde un punto de vista teórico, ese uso paulino podría haber inspirado -a través de una nueva enunciación paródica- la interpretación rabínica posterior.

De todos modos, esta posibilidad, parece poco probable. Exigiría atribuir al fenómeno judeocristiano un peso dentro del judaísmo del s. I d.C. demasiado grande, y del que los datos históricos no parecen haber dejado huella suficiente.

La opción que exploramos aquí implicaría que el autor de Efesios identificase a Jesús con el Dios manifestado en la historia sagrada de Israel, que era actualizada en el culto. Además, ese uso cristiano provocaría una reacción paródica desde el judaísmo rabínico. Es decir, usando la misma palabra común antigua e imitando el uso paulino, algún autor judío opondría su universo de referencias centrado en la figura de Moisés y en la Torah.

\subsubsection{Opción c: No hay dependencia entre Ef y Tg Sal/Syr}

Para finalizar esta sección, debemos aceptar como la hipótesis con mayores probabilidades de verosimilitud aquella que afirma que la comprensión recogida en $\mathrm{Tg}$ y Syr, y la que expresa Ef, se elaboraron de modo independiente desde TM y LXX. De ese modo, ambas visiones obedecerían a una polémica oculta, es decir, a una oposición al discurso tradicional de Sal 68,19 en dos líneas diferentes, una centrada en el pensamiento rabínico mosaico y otra en el judeocristianismo primitivo centrado en Jesucristo.

\section{Conclusiones}

En 1961 Samuel Sandmel llamó la atención sobre el peligro denominado paralelomanía. Con ese término quería denunciar las reconstrucciones históricas hipotéticas basadas en las posibles dependencias textuales entre documentos. El estudio exclu- 
sivo de los textos no parece resolver el problema y desemboca en una cierta locura. Sin embargo, con el enfoque de la estilística sociológica sí se pueden individuar los procesos implicados, trascendiendo la materialidad de los textos, y acudiendo al debate entre los distintos puntos de vista implicados en el debate social.

Las tipologías en los usos del lenguaje en la relación intertextual entre Jc 5,12; Sal 68,19 y Ef 4,8 ofrecen instrumentos precisos todavía poco utilizados en los estudios bíblicos. Desde el punto de vista del estudio del debate de ideas, que son anteriores a los documentos, podemos decir que las intuiciones de Bajtín nos ayudan a comprender mejor cómo funciona el entretejerse de los discursos. Además, se pueden percibir mejor la bivocidad presente en las citas, y el debate ideológico que manifiestan. Ya no vemos una «cita errónea», sino un debate de puntos de vista: un diálogo entre modos de comprender el mundo.

Es claro que el uso de Sal 68,19 tanto en Tg Sal como en Ef 4,8 sorprende porque se cita el salmo haciendo un cambio de su texto. Eso sólo puede aceptarse si algo importante ha acontecido. Para la mentalidad actual, todo hace pensar en un uso fraudulento de un documento que gozaba de autoridad, lo cual resulta difícil de aceptar. Sin embargo, es claro también que los autores antiguos no usaban los documentos como se hace actualmente en la bibliografía científica. Llegados a este punto pensamos haber fundamentado las intuiciones realizadas por Ehorn en su monografia.

En el caso que nos ocupa, lo más razonable es pensar que el texto de Sal 68,19 está detrás y es conocido, pero la palabra nueva que se pronuncia no sólo la conoce, sino que la desarrolla y completa; por lo tanto, no se reproduce un objeto del pasado, sino que se enuncia una novedad teniendo como trasfondo un elemento anterior conocido con el que se establece un diálogo. El traductor arameo y el autor de Efesios dicen lo que quieren decir y lo hacen teniendo en cuenta (no tanto citando) una palabra ajena dotada de autoridad. Lo que dicen no es mera repetición: es el resultado de un nuevo modo de ver el mundo cuando éste ha cambiado. Asistimos así a un fenómeno dialógico constante en la historia: la convivencia entre tradición y desarrollo.

\section{Bibliografía}

Allen, G., 2000, Intertextuality. The New Critical Idiom, London-New York.

Bajtín, M., 1986, Problemas de la poética de Dostoievski, (trad. esp.), México D.F.

Bajtín, M., 1989, Teoría y estética de la novela, (trad. esp.), Madrid.

O’Day, G. R., 1999, “Intertextuality”, en Hayes, J. H. (Ed.), Dictionary of Biblical Interpretation, Nashville, 546-548.

Ehorn, S. M., 2012, "The Use of Psalm 68(67).19 in Ephesians 4.8: A History of Research", CBR 12, 96-120.

Ehorn, S. M., 2014, The Citation of Psalm 68(67).19 in Ephesians 4.8 within the Context of Early Christian Uses of the Psalms, (Thesis), University of Edinburgh, https://www.era. lib.ed.ac.uk/handle/1842/17946?show=full [acceso: 20.09.18].

Elliger, E. - Rudolph, W. (Ed.), 1967-19775, Biblia Hebraica Stuttgartensia, Stuttgart.

Fernández Marcos, N.-Spottorno Díaz-Caro, M. V. (Coords.), 2011, La Biblia Griega Septuaginta. II Libros históricos, Salamanca.

Fernández Marcos, N.-Spottorno Díaz-Caro, M. V. (Coords.), 2013, La Biblia Griega Septuaginta. III Libros poéticos y sapienciales, Salamanca. 
Fitzmyer, J. A., 1984, “The Ascension of Christ and Pentecost”, Theological Studies 45, 408440.

González, E., 2016, "Hermenéutica y teología en la interpretación paulina del AT. Un status quaestionis", Scripta Theologica 48 405-423.

González, E., 2017, “Cristo como mediador ( $\mu \varepsilon \sigma^{\prime}$ in $)$ en el NT”, Scripta Theologica 49, 279299.

Harris, W. H., III, 1988, The Descent of Christ in Ephesians 4:7-11. An Exegetical Investigation with Special Reference to the Influence of Traditions about Moses Associated with Psalm 68:19, (Thesis), University of Sheffield, http://etheses.whiterose.ac.uk/3469/ [acceso: 20.09.18].

Hays, R. B., 1989, Echoes of Scripture in the Letters of Paul, New Haven-London.

Hays, R. B., 2005, The Conversion of the Imagination: Paul as Interpreter of Israel's Scripture, Grand Rapids, Michigan.

Hays, R. B., 2009, Reading the Bible Intertextually, Wako, Texas.

Hays, R. B., 2016, Echoes of Scripture in the Gospels, Wako, Texas.

Kraus, H. J., 1993-1995, Los Salmos, 2 vols., Salamanca.

Lincoln, A. T., 1982, “The Use of OT in Ephesians”, JSNT 14,16-57.

Mandolfo, C., 2007, "Dialogic Form Criticism: An Intertextual Reading of Lamentations and Psalms of Lament”, en Boer, R. (Ed.), Bakhtin and Genre Theory in Biblical Studies (Semeia Studies 63), Atlanta, 69-90.

Milán, F., 2016, “Biblia e intertextualidad: una aproximación”, Scripta Theologica 48, 357379.

Morris, P. (Ed.), 2009, The Bakhtin Reader. Selected Writings of Bakhtin, Medvedev, Voloshinov, London.

Nestle, E. \& E. - Aland, B. \& K. - Karavidopoulos, J. - Martini, C, M. - Metzget, B. M. (Eds.), 2012 28, Novum Testamentum graece, Stuttgart.

Rahlfs, A. (Ed.), 1979², Septuaginta. Id est Vetus Testamentum graece iuxta LXX interpretes, Stuttgart.

Rahlfs, A. (Ed.), $1967^{2}$, Psalmi cum odis, en Septuaginta: Vetus graece auctoritate Societatis Göttingensis editum, vol. 10, Göttingen.

Rubinkiewicz, R., 1975, "Ps LXVIII 19 (=Eph IV 8). Another textual tradition or targum?”, NT 17, 219-224.

Sandmel, S., 1962, "Parallelomania", JBL 81,1-13.

Schökel, L. A., 1992-1993, Salmos: traducción introducciones y comentario, 2 vols., Estella.

Scholtus, S., 2010, "Exegesis e interpretación paulina de Salmos 68:18 en Efesios 4:8-10", DavarLogos 9, 171-186.

Smith, G. V., 1975, "Paul's Use of Psalm 68:18 in Ephesians 4:8”, JETS 18, 181-189.

Stafford, J. R., 2013, "Paul's Use of the Psalms. Beyond Midrash", Perichoresis 11, 211-220.

Stec, D. M. (Ed.), 2004, The Targum of Psalms, (trad. ingl.), Collegeville, Minn.

Volóshinov, V. N., 2009, El marxismo y la filosofía del lenguaje: (los principales problemas del método sociológico en la ciencia del lenguaje), Buenos Aires.

Walter, D. M., (Ed.), 1980, The Old Testament in Syriac According to the Peshitta Version, II.3: Book of Psalms, Leiden.

Zenger, E. - Hossfeld, F.-L., 2005, Psalms 2: A Commentary on Psalms 51-100, Minneapolis. 